\title{
Os territórios rurais do ministério do desenvolvimento agrário
}

RESUMO: Este trabalho é uma discussão sobre a categoria território nas chamadas Políticas Territoriais do Ministério do Desenvolvimento Agrário (MDA) e seus artifícios de acesso à terra. A falácia desenvolvimentista que recheia as propostas do MDA corrobora com o discurso que apresenta o rural como o lócus do atraso, cujo "desenvolvimento precário" perpassa os ideais de um meio onde as desvantagens persistem. O rural seria concebido, segundo essa lógica, como um espaço com deficiências, que necessita de incentivos e planejamentos para que consiga caminhar nos trilhos do desenvolvimento. É observável, todavia, que as aplicações de recursos que aceleram a circulação, a reprodução e a acumulação do capital não necessariamente têm contribuído para alterar os quadros sociais nos municípios que compõem o interior cearense.

\section{The territories of the ministry of rural development}

\begin{abstract}
This paper is a discussion about the category in the territory called Territorial Policies of the Ministry of Agrarian Development (MDA) and its devices to access land. The developmentalist fallacy that fills the MDA supports the proposals with a speech that presents the countryside as the locus of the delay, which "underdeveloped" permeates the ideals of an environment where the disadvantages persist. The country would be designed according to this logic, as a space with disabilities who require incentives and planning so you can walk on the tracks of development. It is observable, however, that the investment of resources that accelerate the circulation, reproduction and accumulation of capital does not necessarily have contributed to changing the social frameworks in the municipalities that make up the interior of Ceará.
\end{abstract}

\section{Paulo Valdenor Silva de Queiroz*}

*Mestre em Geografia, Universidade Estadual do Ceará, UECE, Brasil.

Palavras-chave:

Desenvolvimento; Território; Políticas Públicas; Agricultura Familiar; Geografia.

Key-words: Development; Territory; Public Policy; Family Farming; Geography. 


\section{Introdução}

O Governo Federal brasileiro decidiu, desde 2003, pela elaboração da política nacional de apoio ao Programa Nacional de Desenvolvimento Sustentável dos Territórios Rurais (PRONAT). O principal resultado dessa política foi a criação da Secretária de Desenvolvimento Territorial (SDT), na esfera do Ministério do Desenvolvimento Agrário (MDA), sendo o referido programa acolhido no âmbito do Plano Plurianual do Brasil de 2004 - 2007.

Em sua política, o MDA propôs 0 apoio à agricultura familiar, à reforma agrária e ao incremento da agricultura, propostas estas pautadas em políticas territoriais descentralizadas, participativas e sustentáveis. Tal proposição está expressa em alguns documentos, tais como:

- Referências para um programa o desenvolvimento territorial sustentável (de junho de 2003);

- Referências para uma Estratégia de Desenvolvimento Rural Sustentável no Brasil (de março de 2005);

- Marco Referencial para Apoio ao Desenvolvimento de Territórios Rurais (de maio de 2005); e

- Referências para a Gestão Social dos Territórios Rurais: guia para o controle social documento de apoio n ${ }^{0} 04$ - (de maio de 2006).

O enfoque territorial é apresentado na visão da SDT/MDA como elemento integrador dos espaços, dos agentes sociais (produtores e consumidores deste espaço), dos mercados e das políticas locais. Já os territórios rurais são representados pelos espaços onde predomina o que 0 MDA chama de "elementos rurais" (apresentados como um ambiente natural pouco modificado e/ou parcialmente convertido pela atividade agrossilvopastoril; baixa densidade demográfica; base na economia primária etc.). Nestes territórios estão inclusos os espaços urbanizados que compreendem pequenas e médias cidades, vilas e povoados.

Grande parte das políticas implantadas para o meio rural nas últimas décadas caminha dentro do chamado paradigma do capitalismo agrário, ao assegurar que único futuro para o meio rural está na transformação do camponês em um agricultor familiar, cuja produção é voltada para o mercado.

Essa agricultura familiar, vista à luz do paradigma do capitalismo agrário, é descrita pela intensa presença do trabalho assalariado e conhecida por seu perfil econômico-quantitativo na exploração da terra.

Assim, toda a abordagem, ao analisar a materialidade dessas ações políticas, sob determinada dimensão, visa compreender os mecanismos mediante os quais a sociedade interage com o espaço (compreendido como condição, condicionante e meio), na produção de um espaço geográfico.

\section{O Estado interventor e as ações contraditórias para o desenvolvimento}

Geografia Ensino \& Pesquisa, v. 15, n.2, p. 117128, maio./ago. 2011 Os territórios rurais do ministério do desenvolvimento agrário

Para Castro (2005, p. 118), "o Estado é na realidade uma instituição e como tal está inscrito nos tempos do território e da sociedade". Isso ocorre porque uma das condições do Estado é a de interventor. Essa qualidade sanciona a ele um conjunto de instrumentos legais, que the facultam uma complexa gama de possibilidades de ação em suas variadas relações (econômicas, jurídicas, políticas, ambientais etc.) de (re)produção da/na ordem social. São as 
chamadas intervenções de ordem pública ou simplesmente políticas públicas, pois segundo seus princípios gerais, tais medidas se destinam a atender uma considerável parcela da população (pelo menos teoricamente).

As ações do Estado, todavia, não se dão ao acaso. E muito menos se processam de modo neutro, como se fosse uma instituição que governasse fundamentada em princípios de equilibrio social, econômico, político e espacial, pairando acima das classes sociais e de seus conflitos. Pelo contrário, as condições de realização do Estado capitalista moderno representam a efetivação e a (re)produção de uma sociedade capitalista, isto é, a valorização das relações de troca que viabilizam a acumulação e a (re)produção da sociedade de classes. É justamente neste ponto que reside a dialética dos mecanismos de (re)determinação do Estado capitalista que, de um lado, segrega as classes, ao mesmo tempo em que mantém todas dentro da mesma égide fetichista do consumo desenfreado.

O desenvolvimento geográfico desigual, como chamou Harvey (2000), ou desenvolvimento desigual e combinado, como diz Corrêa (1986), reflete o desempenho espacialmente desigual do Estado capitalista moderno como provedor de serviços públicos, especialmente aqueles que servem à população. Referem-se ao fato de que cada um destes aspectos da realidade é constituído de dois processos relacionados e interpenetrados, apesar de serem diferentes e opostos. "A contradição que daí decorre é característica imanente à realidade e o elemento motor de sua transformação". (CORRÊA, 1986, p. 42).

Segundo Pedro Jacobi, em seu texto Estado Capitalista: Transformações na dinâmica de intervenção e papel das burocracias, publicado em 1987,

[As políticas sociais estão] permeadas pelas contradições e tensões entre os imperativos da reprodução do capital e as necessidades de reprodução da força do capital. E o Estado acaba por se tornar interlocutor das demandas sociais dos diferentes movimentos reivindicatórios e indutor das políticas que regulam a dinâmica geral da sociedade. (p. 114).

As políticas públicas agrárias aparecem frequentemente associadas a conflitos no campo, sendo, portanto, modos de intervenção com a finalidade de reduzir as tensões sociais, procurando um consenso. Logo, as políticas públicas não se afirmam como medida sólida de resolver as constantes manifestações de luta pela terra tão presente desde o Brasil Colonial.

No contexto do desenvolvimento desigual das relações que caracterizam o sistema capitalista, a compreensão do campesinato em sua dinâmica histórico-político-social, é a de uma classe que se diluiu com a modernização da agricultura em meados do século XX. Some-se isso ao fato de haver políticas que orientam ideologicamente outras nomenclaturas para esta classe, como: agricultores, pequenos proprietários, sitiantes, lavradores etc.

É pela própria lógica da desigualdade das relações sociais, todavia, que o camponês não pode desaparecer. Assim, entende-se que o conceito de agricultor camponês continua a existir, mesmo com algumas alterações da Modernidade, e que este permite vislumbrar uma unidade de classe que se manifesta na ordenação das parcelas do território sob seu controle. Como classe sui generis, sua singularidade se manifesta na habilidade que tem de reproduzir o espaço ao seu redor, pois ainda há o efetivo controle sobre o trabalho e os meios de produção. Isto "é o que Ihes permite conservar a capacidade de produzirem seus próprios meios de vida, ainda que as condições concretas de reprodução de cada família nem sempre assim o determine". (PAULINO, 2003, p. 9).

Geografia Ensino \& Pesquisa, v. 15, n.2, p. 117-128, maio./ago. 2011

Queiroz, P. V. S. 
O espaço geográfico possui uma gênese, uma estrutura, características, processos e funções. Dizia Milton Santos (1997) que, é um "acumulado de tempos desiguais", constituído historicamente com significado e realização para a consciência humana.

Nestas circunstâncias, compreende-se que o território deve ser apreendido como um espaço no qual se projetou um trabalho, e que, por consequência, revela uma complexa teia de relações sociais marcadas por conflituosas relações de poder. Dessa forma, ele só pode ser compreendido com amparo em todas as dimensões que o constituem (política, social, econômica e cultural).

É assim que se vê a abordagem territorial da SDT/MDA. Com um discurso aparentemente novo em suas políticas traz, a falsa ilusão de que uma nova perspectiva é direcionada àquele que durante muitos anos foi considerado o "primo pobre" do meio urbano: o rural. 0 padrão de desenvolvimento utilizado por tais políticas, no entanto, continua a ser um arquétipo amplamente marcado pela áurea aptidão do consumo e de acumulação de riqueza.

Por esta e outras razões, afirma-se que no fundo a persistência das desigualdades no meio rural está na concentração da riqueza social historicamente produzida, que tem origem nas dificuldades criadas (pelo sistema capitalista) ao acesso e distribuição de bens e serviços de qualidade, à satisfação das necessidades e capacidades humanas.

O Estado moderno é capitalista, logo, suas ações também o são. Dessa forma, políticas de desenvolvimento oriundas das ações do Estado não podem (nem poderão) acabar com as contradições de classe inerentes ao sistema. Também não se nega, todavia, que avanços podem ser dados em direção à melhorias sociais. Para isso, entretanto, é preciso aceitar que transformações importantes deverão ocorrer no seio da própria sociedade (que dá vida ao capital), com o estabelecimento de padrões de desenvolvimento mais coerentes e sustentáveis em todos os setores, continuamente aprimorados por meio de ordenamentos dinâmicos democraticamente conduzidos. Há uma apropriação da riqueza e socialização dos prejuízos que deve ser combatida.

As oportunidades criadas, porém, persistem em trilhar o caminho de uma produção mercadológica. Insistem na noção de que a miséria e os conflitos no campo serão resolvidos via mercado, havendo mais dinheiro, mais empréstimos etc.

Considerando as proposições, pelo MDA, da criação de territórios (rurais), como ferramenta de apoio à agricultura familiar, no item a seguir serão vistos alguns traços que marcam e fundamentam a aplicação de tais medidas no meio rural brasileiro.

\section{Território: categoria analítica da Geografia}

Ao se pensar numa análise conceitual da categoria território, faz-se necessária a compreensão, segundo Raffestin (1993), de que o espaço é anterior ao território. O território se forma do espaço e resulta de uma ação conduzida por um agente sintagmático, que se apropria de um espaço, concreto ou abstratamente, tornando-o um território.

O território, nessa perspectiva, é o espaço no qual se projetou um trabalho, e que, por consequência, revela uma complexa teia de relações sociais marcadas por conflituosas vinculações de poder. Dessa forma, o espaço é a "prisão original, o território é a prisão que os homens constroem para si [...] Evidentemente, o território se apóia no espaço, mas não é 0 espaço. É uma produção, a partir do espaço". (RAFFESTIN, 1993, p. 144). 
O espaço, assim, preexiste a qualquer ação. O espaço é, de certa forma, "encarado" como matéria-prima, um local de possibilidades materiais pré-existentes a qualquer conhecimento e a qualquer prática relacional; espaço este que se reconfigura desde o momento em que um agente qualquer manifeste a intenção de dele se apoderar. Este espaço representa muito bem aquilo que Milton Santos chama de Primeira Natureza, ou "Natureza Natural", cuja existência só se pode admitir num momento imediatamente anterior àquele no qual o homem se transformou em homem social pelo ato da produção social (SANTOS, p. 1992).

Para Bernardo Mançano Fernandes (2005, p. 26), "o território é o espaço apropriado por uma determinada relação social que o produz e o mantém a partir de uma forma de poder".

Assim, percebe-se que não é possível estudar o território sem compreender o espaço e seu processo de fragmentação, que criam os territórios. Desse modo, pode-se dizer que as dimensões espaciais nos situam ante a articulação sociedade - espaço, na medida em que a produção da vida social, no cotidiano do indivíduo, não representa apenas a produção de bens para a satisfação das necessidades materiais, mas também a produção da humanidade do homem, colocando-nos diante da produção social do mundo (CARLOS, 1997, p. 306).

Os mecanismos de apropriação desigual fragmentam os espaços e os tornam, desde determinações específicas, mercadorias, que, como propriedades privadas, podem ser compradas e vendidas aos pedaços.

A compra e a venda do espaço, quer seja no espaço urbano ou no agrário, determina que haja uma apropriação diferenciada da dimensão espacial. A apropriação diferenciada envolve relações de poder, essenciais para manutenção e criação dos territórios. Para Castro (1992),

[...] 0 território é uma unidade geográfica, mas é também uma unidade social e uma unidade política. Podemos falar então em espaço-territorial, que constitui um sistema de estruturas tanto sociais como espaciais, estabelecido através da ação humana sobre a natureza. (p. 29).

Como já expresso, o debate central sobre o território envolve seu caráter absoluto ou relacional. O território estabelecido a partir da perspectiva relacional do espaço é visto completamente inserido em relações sócio-históricas, ou, para muitos autores (FERNANDES, 1999; RAFFESTIN, 1993; SOUZA, 1995), em relações de poder.

Existem várias outras pospostas de se estudar o território. Haesbaert (2004) ressalta que as variações conceituais de análise do território podem ser agrupadas em três grandes vertentes básicas:

- Política (referida às relações espaço-poder em geral) ou jurídico-política, (relativa também a todas as relações espaço-poder institucionalizadas): a mais difundida, onde o território é visto como um espaço delimitado e controlado, através do qual se exerce um determinado poder, na maioria das vezes - mas não exclusivamente - relacionado ao poder político do Estado.

- Cultural (muitas vezes culturalista) ou simbólico-cultural: prioriza a dimensão simbólica e mais subjetiva, em que o território é visto, sobretudo, como o produto da apropriação/valorização simbólica de um grupo em relação ao seu espaço vivido.

- Econômico (muitas vezes economicista): menos difundida, enfatiza a dimensão espacial das relações econômicas, o território como fonte de recursos e/ou incorporado no embate entre classes sociais e na relação capital-trabalho, como produção da divisão 'territorial' do trabalho, por exemplo. (HAESBAERT, 2004, p. 40).

Geografia Ensino \& Pesquisa, v. 15, n.2, p. 117-128, maio./ago. 2011

Queiroz, P. V. S. 
Para cada vertente, há um conjunto de elementos norteadores do conceito. A vertente política, a mais difundida entre todas, como visto em algumas referências retrocitadas, possui como elemento central de sua análise o poder.

$O$ poder tem um significado muito forte para o conceito de território, todavia, deve-se ter a clareza de que tal elemento possui único objetivo: 0 da legitimação. A (re)formulação do pensamento ideológico faz com que parte da população passe a legitimar os poderes de determinados indivíduos.

O território pode assim ser descrito como interação conjunta de um espaço (socialmente produzido) com a ação humana (raramente isolada), expressos nas formas e nas alterações que a ação dos indivíduos produz sobre a base física e natural em que se encontram.

\title{
Considerações sobre o território nas políticas de desenvolvimento rural do MDA
}

$\mathrm{Na}$ abordagem das políticas territoriais, o foco é direcionado para o território. Para a SDT/MDA, as políticas territoriais se comportam como importantes políticas de ordenamento territorial, de autonomia, autogestão, assim como servem de complemento das políticas (neoliberais) de descentralização.

Assim, o território é definido como

\begin{abstract}
Um espaço físico, geograficamente definido, geralmente continuo, compreendendo cidades e campo, caracterizado por critérios multidimensionais, tais como o ambiente, a economia, a sociedade, a cultura, a política e as instituições, e uma população, com grupos sociais relativamente distintos, que se relacionam interna e externamente por meios de processos específicos, onde se pode distinguir um ou mais elementos que indicam identidade e coesão social, cultural e territorial. (MDA/SDT, 2003, p. 34).
\end{abstract}

O desenvolvimento rural, circunscrito a um quadro territorial, descarta a análise setorial (e regional), no desafio de integrar o agricultor à indústria e de criar condições para que a população valorize um certo território num conjunto muito variado de atividades e de mercados (SDT/MDA, 2003, p. 4). "Na perspectiva territorial, as dicotomias e os antagonismos são substituídos pelo escrutínio da diversidade de ações, estratégias e trajetórias que os atores (indivíduos, empresas ou instituições) adotam visando sua reprodução social e econômica. (SCHNEIDER, 2004, p.105)".

Schneider (2004, p. 94) enfatiza a noção de que, fora do Brasil, as discussões sobre o desenvolvimento rural conferem espaço e que a efetivação desses debates aparece moldada em quatro elementos-chave: "a erradicação da pobreza rural, a questão do protagonismo dos atores sociais e sua participação política, o território como unidade de referência e a preocupação central com a sustentabilidade".

Para Schejtman e Berdegué (2004), investigador principal e presidente, respectivamente, da Rede Internacional de Metodologia de Investigação de Sistemas de Produção/Centro Latinoamericano para el Desarrollo Rural (RIMISP) o desenvolvimento rural aparece definido como, rural determinado, cuja finalidade é reduzir a pobreza rural. A transformação 
produtiva tem o propósito de articular competitiva e sustentavelmente a economia do território a mercados dinâmicos. O desenvolvimento institucional tem os propósitos de estimular e facilitar a interação e a formação dos atores locais entre si e entre eles com os agentes externos relevantes, assim como de incrementar as oportunidades para que a população pobre participe do processo e de seus benefícios. (SCHEJTMAN; BERDEGUÉ, 2004, p. 13, tradução nossa).

No Brasil dois intelectuais são os responsáveis pela definição de como aparece 0 desenvolvimento rural brasileiro: José Eli da Veiga (O Brasil rural precisa de uma estratégia de desenvolvimento, de 2001) e Zander Navarro (Desenvolvimento rural no Brasil: os limites do passado e os caminhos do futuro, de 2001). Para o primeiro, o desenvolvimento nos territórios rurais aparece ligado às ideias de valorização e fortalecimento da agricultura familiar, à diversificação das economias dos territórios, ao estímulo do empreendedorismo local e auxílio do Estado na formação de arranjos institucionais locais. Já para Navarro, "[a] noção de desenvolvimento rural estaria relacionada com as inquietações sociais, típicas da época atual, em que mais do que haver clareza sobre seu significado e características, o que existe é uma incógnita em relação à sua própria possibilidade". (SCHNEIDER, 2004, p. 97).

Para Schneider (2004), o tema do desenvolvimento rural nas políticas públicas parece atribuir relevância ao enfoque territorial, servindo como uma importante unidade de análise conceitual e de referência normativa para o tema. 0 autor assevera, então, que

\begin{abstract}
A emergência da abordagem territorial do desenvolvimento rural pressupõe que o nível adequado de tratamento analítico e conceitual dos problemas concretos deva ser o espaço de ação em que transcorrem as relações sociais, econômicas, políticas e institucionais. Esse espaço é construído a partir da ação entre os indivíduos e o ambiente ou contexto objetivo em que estão inseridos. Portanto, o conteúdo desse espaço é entendido como o território. Mas não se trata apenas do entendimento teórico e abstrato, pois esta perspectiva também propõe que as soluções e respostas normativas aos problemas existentes nesses espaços encontram-se nele mesmo. (p. 99).
\end{abstract}

Schneider (2005) assegura que a variável espacial passou a obter grande destaque nos últimos tempos e passou a ser apontada como elemento de fundamental relevância para se compreender o dinamismo (social e econômico) de determinadas regiões. Lembra que o modelo do enfoque territorial está presente nos exemplos:

[do] programa LEADER na União Européia, o programa de empoderamento comunitário nos Estados Unidos, as mesas de concertação e os sistemas locais de produção agrícola no Peru, a produção agroecológica de frutas no Chile e, no Brasil, o Programa Nacional de Desenvolvimento Sustentável de Territórios Rurais (PRONAT), do Ministério do Desenvolvimento Agrário (MDA). (p. 2).

No que concerne aos fatores que proporcionaram a emergência da abordagem territorial como tentativa de sistematizar as discussões sobre o desenvolvimento rural, Schneider (2004) apontar dois processos distintos.

O primeiro, diz respeito ao suposto esgotamento teórico e prático da abordagem regional, tornando evidentes os limites desta noção de referência para se pensar as ações e políticas públicas de desenvolvimento rural. Segundo o autor,

Geografia Ensino \& Pesquisa, v. 15, n.2, p. 117-128, maio./ago. 2011

Queiroz, P. V. S. 
O desgaste da noção de região e, mais precisamente, de desenvolvimento ou planejamento regional, inicia-se com a [suposta] crise da capacidade de intervenção macroeconômica e macrossocial do Estado, que ocorre a partir de meados da década de 1970 e se agudiza na década seguinte, especialmente com a influência crescente do ideário neoliberal sobre as perspectivas keynesianas que vigoravam desde o final da Segunda Guerra Mundial. (SCHNEIDER, 2004, p. 100).

Assim, a abordagem regional perde seu poder explicativo, como referência teórica e conceitual, tornado-se insuficiente para cumprir o papel de instrumento eficaz de planejamento, práticas e ações do Estado.

O segundo elemento, que torna importante a emergência da abordagem territorial nas políticas públicas, "está baseado no questionamento crescente da dinâmica setorial de ramos da atividade econômica que passaram a se desenvolver muito mais a partir de uma lógica de escopo do que de escala". (SCHNEIDER, 2004, p. 103).

Levando em conta o fato de que (segundo essas argumentações) era preciso acionar uma nova unidade de referência para tornar efetivas as ações do Estado, consequentemente, passou-se a adotar o território como elemento articulador das intervenções decorrentes de planejamento que passou a ser denominado de desenvolvimento territorial. E, sob esta áurea, "[...] o território emerge como nova unidade de referência para a atuação do Estado e a regulação das políticas públicas". (SCHNEIDER, 2004, p. 102).

Para Montenegro Gómez (2006), a questão não é tão simples, pois as políticas territoriais do Governo brasileiro insistem

[...] em confiar a regulação socioeconômica a mecanismos de mercado, enfim, em consolidar o paradigma neoliberal que domina o discurso e a prática tanto dos organismos internacionais de regulação e controle como dos governos locais, neste caso, adotando algumas correções e exibindo algumas preocupações que, sob o pretexto de impor limites à lógica do capital, na realidade legitimam uma prática que se insiste em ser a única "possivel". (p. 88).

Para o MDA, os países que possuem proporções iguais às do Brasil "necessitam de políticas públicas ao menos regionalizadas, para que possam melhor implementar os instrumentos adequados à natureza dos problemas e as possíveis soluções". (MDA/SDT, 2003, p. 28). Se "as políticas públicas devem ser regionalizadas" e se há "diversos contextos regionais", por que trabalhar com o conceito de território?

Sem dúvidas, pode-se assinalar que, para a Geografia, o território é bem mais amplo do que é para o MDA. É preciso considerar que cada território é uma totalidade. Essas totalidades fornecem ao território outros atributos tais como: a multidimensionalidade (política, social, ambiental, cultural, econômica etc.), a multiescalaridade e a soberania (FERNANDES, 2008). "Portanto, é impossível compreender o conceito de território sem conceber as relações de poder que determinam a soberania". (FERNANDES, 2008, p. 279).

Para Montenegro Gómez, as intenções de propor a inclusão das perspectivas de um

Geografia Ensino \& Pesquisa, v. 15, n.2, p. 117 128, maio./ago. 2011

Os territórios rurais do ministério do desenvolvimento agrário
[...] tentativas de "humanizar" o capitalismo e reconstruí-lo com um caráter integrador, no entanto, desconhece-se seu caráter destrutivo, amplificador de desigualdades e gerador de exclusão, sob a promessa, nunca cumprida, 
de que, estabelecendo certos mecanismos, a redistribuição da riqueza e a melhora geral da qualidade de vida é possível via mercado. "Esquecese" de que tanto a teoria como a experiência acumulada caminham em sentido oposto: a integração no mercado não melhora a situação da maioria da população, em função da concorrência excludente que se origina; ao contrário, no processo, boa parte sofre uma marginalização crescente. (2006, p. $88-89)$.

No caminho trilhado por este modelo de desenvolvimento, o território é uma estratégia de venda dos espaços para investimentos mercantis. A incorporação da categoria território para a elaboração e implementação de políticas de desenvolvimento não passa de uma normatização do território, apenas na sua face mercadológica.

\section{"Problemas" no Território da política territorial da SDT/MDA}

Entre os critérios metodológicos utilizados para definir os recortes territoriais, está a diferenciação das microrregiões rurais das urbanas. Para a divisão dos municípios em territórios, foi utilizado o parâmetro da densidade demográfica de menos de 80 hab. $/ \mathrm{km}^{2}$, combinada com uma população total média por município de até 50.000 habitantes (SDT/MDA, 2003).

A utilização desse indicador de densidade demográfica revela a apreensão de um conceito de território pouco complexo que forma territórios homogêneos, uma vez que as relações de poder e os conflitos internos próprios desses espaços são desconsiderados.

Raffestin (1993) já alertava para a ideia de que, na conformação de um território, há elementos de fundamental importância, tais como os recursos e a população. Essa tríade raffestaniana (população, território e recursos) é fundamental para o entendimento da conformação dos territórios e dos processos de territorialidades, pois de nada serve um espaço sem população, e também não há território onde se tem população e espaço, porém não existe a legitimação do poder, uma vez que a aceitação do território é essencial para sua manutenção. Logo, a população também é um valioso recurso (RAFFESTIN, 1993).

Para Montenegro Gómez (2006), o reducionismo da categoria território nas proposições das políticas territoriais

[...] induz à elaboração de políticas públicas para o meio rural que tomam o território como simples depositário da intervenção, como receptor de uma ação mais bem direcionada, já que agora se conheceria melhor onde se localiza, graças aos indicadores utilizados, o "verdadeiro" meio rural. Mero receptor, porque o território definido a partir da densidade demográfica não é um território carregado de interações homem-meio, porque perde a miríade de relações entre a sociedade e a natureza, não considera que 0 território está no cerne da dinâmica social. (p. 104).

Além disso, existe outra dimensão que se desconsidera quando se incorpora o molde normativo do território: o conflito. Os territórios são efetivamente marcados pelas mais diversas relações de poder que apontam para uma permanente disputa pela apropriação do espaço. Ao desconsiderar o poder (um componente fundamental e inerente à conformação de territórios), desprezam-se na realidade os interesses de resolver (ou mesmo de demonstrar) os conflitos no interior dos espaços.

Geografia Ensino \& Pesquisa, v. 15, n.2, p. 117-128, maio./ago. 2011

Queiroz, P. V. S. 
Observa-se, assim, uma tentativa de mascarar as relações de poder e o conteúdo economicista, que possui lugar de destaque nas políticas de desenvolvimento. Há uma clara circunscrição dos conceitos de território e desenvolvimento (na finalidade de torná-los práticos) que rompe com seus limites, acarretando numa definição completamente nova, adequada a um viés político-ideológico também novo. Logo, há uma (re)constituição teórica em ambos os pontos, mantendo-os funcionais na sustentação de um processo que de novo não tem nada.

São inúmeras as variações do conceito de território. Se há a necessidade de um território para fins mercantis, certamente, existem definições que servem muito bem a esta finalidade. 0 que aparenta, no entanto, é haver uma confusão acerca da constituição teórica das políticas territoriais. Isto conduz à pergunta: é preciso fazer do território uma política para uma política do território? Muitas vezes, parece que o próprio MDA não sabe qual é a resposta.

Essa simplificação conceitual do território não é algo que surge despretensiosamente, pois, para garantir a eficiência de sua reprodução, o planejamento requer certa consolidação da ordem social e certa estabilidade. "Para traçar uma política de desenvolvimento, é preciso (ou como mínimo desejável) esterilizar os conflitos que possam questionar a legitimidade e a absurdidade da lógica capitalista". (MONTENEGRO GÓMEZ, 2006, p. 102). Desse modo, 0 território como instrumento da abordagem territorial é recortado e moldado para suprir as necessidades de controle social e reprodução capitalista.

\section{Conclusão}

Apesar do conceito de desenvolvimento (territorial) rural sustentável das políticas territoriais da SDT/MDA ter incluído certos aspectos - como a participação, a solidariedade, 0 fortalecimento dos recursos endógenos e identidade territorial - acredita-se que sua finalidade é a transformação do meio rural num espaço amplamente produtivo e totalmente inserido na dinâmica do consumismo desenfreado, não rompendo com o paradigma do capitalismo agrário.

Assim, crê-se que este "desenvolvimento territorial" representa uma política em que o social, uma vez mais, junto com os aspectos sociais, está submisso aos aspectos econômicos, ampliando a lógica do mercado, a reprodução e acumulação de capital. Logo, a ampliação desse modelo de desenvolvimento sobre o campo, representa uma política estratégica de controle dos governos que permite a eles a garantia da reprodução do sistema socioeconômico atuante.

Torna-se claro que nas políticas de desenvolvimento territorial proposta para o campo, o território (como abordagem territorial), não é capaz de comportar toda a carga teórica requerida no valor heurístico/conceitual do território utilizado pela Geografia, já que o propósito da abordagem territorial é a funcionalidade das políticas de planejamento.

Desse modo, aludem-se argumentações na finalidade de diferenciar o conteúdo que 0 território geográfico assume: uma espacialização do poder cuja finalidade e dominação é o controle dos espaços, tornando-os territórios. Enquanto que, na "abordagem territorial" do desenvolvimento, pressupõe apenas um conjunto de ações interventoras sobre o espaço e nas relações sociais nele existentes.

Logo, por mais que haja um esforço para abordar o território além de sua dimensão física, com afirmações do tipo - o território é uma "construção social", são "relações sociais", aglutinam uma "identidade" etc. - acredita-se que esse é um empenho (re)afirmador de um caminho já apresentado: a reprodução e acumulação de capital. 0 território apresentado pelas políticas 
territoriais, juntamente com os elementos que aglutina, são componentes fundamentais de modelo de desenvolvimento capitalista, que reduzem o significado conceitual do território e a questão agrária a termos meramente mercantis.

Nesse discurso, as estratégias territoriais implementadas no Brasil (e fora dele), longe de solucionar os problemas do/no campo, não passam de medidas de controle social que, articuladas com os discursos de desenvolvimento, fazem (ou pelo menos pretendem) um sentido de progresso.

\section{Referências}

CARLOS, Ana Fani de Alessandri. O lugar: mundialização e fragmentação. In: SANTOS, Milton. 0 novo mapa do mundo: fim de século e globalização. São Paulo. Hucitec, 1997. p. 303 - 309.

CASTRO, Iná Elias de. Geografia e política: território, escalas de ação e instituições. Rio de Janeiro: Bertrand Brasil, 2005.

CASTRO, Iná Elias de. 0 mito da necessidade: discurso e pratica do regionalismo nordestino. Rio de Janeiro: Bertrand Brasil, 1992.

CORRÊA, Roberto Lobato. Região e organização espacial. São Paulo: Ática, 1986.

FERNANDES, Bernardo Mançano. Desenvolvimento territorial: conflitualidade e sustentabilidade. Brasilia: CONDRAF, 2005.

FERNANDES, Bernardo Mançano. Entrando nos territórios do território. In: PAULINO, Eliane Tomiasi; FABRINI, João Edmilson(Org.) Campesinato e territórios em disputa. São Paulo: Expressão Popular, 2008. p. $273-301$

FERNANDES, Bernardo Mançano. MST - Movimento dos Trabalhadores Rurais Sem-terra: formação e territorialização em São Paulo. São Paulo: HUCITEC, 1999.

HAESBEART, Rogério. 0 mito da desterritorialização: do "fim dos territórios" à multiterritorialidade. Rio de Janeiro: Bertrand Brasil, 2004.

HARVEY, David. Espaços de Esperança. Tradução de Adail Ubirajara Sobral e Maria Stela Gonçalves. São Paulo. Loyola, 2004.

JACOBI, Pedro. Estado capitalista: transformações na dinâmica de intervenção e o papel das burocracias. Sociedade e Estado, vol. II, n’os 1 e 2, jan./dez. 1987, pp. 105-115

MINISTÉRIO DO DESENVOLVIMENTO AGRÁRIO. Plano Territorial de Desenvolvimento Rural Sustentável: guia para o planejamento (Documento de apoio nº 02). Brasília: MDA/SDT, 2005.

MINISTÉRIO DO DESENVOLVIMENTO AGRÁRIO. Referência para a Gestão Social dos Territórios Rurais: guia para o controle social (Documento de apoio nº4). Brasília: MDA/SDT, 2006.

MINISTÉRIO DO DESENVOLVIMENTO AGRÁRIO. Referência para a Gestão Social de Territórios Rurais (Documento institucional $n^{\circ}$ 03). Brasília: MDA/SDT, 2005b.

MINISTÉRIO DO DESENVOLVIMENTO AGRÁRIO. Referências para um programa o desenvolvimento territorial sustentável. SDT/CONDRAF, 2003.

MONTENEGRO GÓMEZ, Jorge R. Desenvolvimento em (des)construção: narrativas escalares sobre desenvolvimento territorial rural. 2006. 438p. Tese (Doutorado em Geografia)-UNESP, Presidente Prudente, 2006.

PAULINO, Eliane Tomiasi. Terra é vida: a Geografia dos camponeses no norte do Paraná. 2003. 429p. Tese (Doutorado em Geografia)-UNESP, Presidente Prudente, 2003.

Geografia Ensino \& Pesquisa, v. 15, n.2, p. 117-128, maio./ago. 2011

Queiroz, P. V. S. 
RAFFESTIN, Claude. Por uma geografia do poder. Tradução de Maria Cecilia França. São Paulo: Ática, 1993.

SANTOS, Milton. A natureza do espaço. São Paulo: HUCITEC, 1997.

SANTOS, Milton. Espaço e método. 3.ed. São Paulo: NOBEL, 1992.

SCHEJTMAN, Alexander; BERDEGUÉ, Julio A. Desarrollo territorial rural. Debates y temas rurales. Santiago de Chile, n. 1., 2004. Disponível em: <http://www.rimisp.org/ getdoc.php?docid=870>. Acesso em: janeiro de 2009.

SCHNEIDER, Sergio. A abordagem territorial do desenvolvimento rural e suas articulações externas. Sociologias, Porto Alegre, nº. 11, p. 88-125, jan.jjun. 2004.

SCHNEIDER, Sergio; TARTARUGA, Ivan G. Peyré. Do território geográfico à abordagem territorial do desenvolvimento rural. In: Jornadas de Intercambio y discusión: el desarrollo rural en su perspectiva institucional y territorial, 1., 2005, Buenos Aires. Disponível em: $<$ <htp://www.ufrgs.br/PGDR/textosabertos/sergio_e_tartaruga.pdf>. Acesso em: abril de 2008.

SOUZA, Marcelo José Lopes de. O território: sobre o espaço e poder, autonomia e desenvolvimento. In: CASTRO, Iná Elias de; GOMES, Paulo César da Costa; CORREAA, Roberto Lobato (Org.) Geografia: conceitos e temas, Rio de Janeiro: Bertrand Brasil, 1995. p. 77-116.

\section{Correspondência}

Paulo Valdenor Silva de Queiroz — Rua General Rangel, 41. CEP: 60.455-465. Bairro Amadeu Furtado. Fortaleza - Ceará

E- mail: pauloufc2003@yahoo.com.br

Recebido em 18 de julho de 2011.

Revisado pelo autor em 24 de agosto de 2011

Aprovado em 26 de agosto de 2011.

Geografia Ensino \& Pesquisa, v. 15, n.2, p. 117 128, maio./ago. 2011 